\title{
Predictive Factors Increasing the Risk of Radiation Toxicity in Patients with Early Breast Cancer
}

\author{
Asmaa A Abdeltawab*, Samia A Ali, Hanan G Mostafa, Mohamed A Hassan
}

\begin{abstract}
Objectives: Radiation induces adverse events on healthy tissues which may be augmented by certain factors. This study aimed to assess patients; tumor and treatment-related factors which increase the risk of radiation-induced toxicity in breast cancer patients. Methods: This prospective study included postmenopausal early breast cancer patients treated at the clinical oncology department, Assiut University, Egypt between January 2015 and December 2018. Patients treated with mastectomy followed by conventional radiotherapy $(25 \mathrm{x} 2 \mathrm{~Gy})$ and either concurrent or sequential letrozole. Acute and late radiation toxicity was scored according to EORTC/RTOG and risk factors were analyzed. Results: A total of 75 patients were included in the study. After a median follow-up of 24 months, 12 patients had $>$ grade 2 acute dermatitis, 5 patients had $>$ grade 2 cardiac toxicity and 3 patients had $>$ grade 2 lung toxicity. Multivariate analysis revealed that trastuzumab use was associated with a decrease risk of acute dermatitis $(\mathrm{p}=0.01)$ but boost irradiation was significantly associated with increased risk of acute dermatitis $(p=0.01)$. Late toxicity $>$ grade 2 was observed in 6 patients, 14 patients, and 2 patients for skin, heart, and lung respectively. Conclusion: The use of boost irradiation was associated with increased risk of acute dermatitis, in the contrary; the use of trastuzumab seemed to be protective as observed in this study.
\end{abstract}

Keywords: Breast cancer- conventional radiotherapy- normal tissue toxicity- risk factors

Asian Pac J Cancer Prev, 22 (1), 145-149

\section{Introduction}

Breast cancer is the second most commonly diagnosed cancer $(11.6 \%)$ in both sexes after lung, among females, breast cancer is the most commonly diagnosed cancer, and it is the leading cause of cancer death (Bray et al., 2018). Radiotherapy has major advantages in the treatment of breast cancer. It reduces the risk of locoregional recurrences and improves overall survival both for early-stage breast cancer after breast-conserving surgery and after mastectomy for locally advanced disease (Darby et al., 2011). Unfortunately, these advantages were accompanied by a number of adverse effects to the heart, lungs, and the opposite breast tissue (Jagsi et al., 2007). Radiation-induced lung injury (RILI) was originally described in 1925 and divided into an acute injury stage, radiation pneumonitis (RP), and chronic injury stage, radiation pulmonary fibrosis (RPF) (Bradley and Movsas, 2008). Radiation pneumonitis occurs within 6 months of therapy (mostly within 12 weeks), while RPF occurs $>1$ year following therapy (Yarnold et al., 2010; Bernchou et al., 2013). Despite of most patients receiving thoracic irradiation are at risk for RILI, several factors may modify their risk. Patient-related factors as history of smoking, chronic obstructive pulmonary diseases, and interstitial lung disease are all lead to increased risk (Chen et al., 2017). In patients with breast cancer, old age, concurrent use of chemotherapy/ tamoxifen, chest wall irradiation with electrons, and supraclavicular field irradiation are correlated with increased risk (Jeba et al., 2015). Besides, systemic therapy like chemotherapy, targeted therapy, and immunotherapy has all been played a role in cases of radiation recall pneumonitis (Vogelius et al., 2012; Burris et al., 2010).

Conformal external beam radiation planning decreases the irradiated volumes through maximizing dose delivery to target and spares the healthy tissues. Emerging clinical, radiographic predictors of lung injury and serologic tests may lead to further risk-adaptive radiation planning (Ebert et al., 2015). Regarding radiation-induced adverse events to the heart, the use of opposed tangential portals exposes it to a significant amount of radiation doses, especially when left-sided chest wall is treated. Three-dimensional conformal RT intensity-modulated RT providing better normal tissue sparing. Radiation-induced cardiomyopathy results from slowly evolving lesion (diffuse fibrosis) leading to impaired function. The use of two-dimensional treatment with cobalt 60 is still prevalent in developing countries which increases the normal tissue complication probability (Khan et al., 2014). 
Most (74-100\%) of the patients undergoing radiotherapy of the breast develop skin adverse events such as erythema, desquamation, and edema (Lopez et al., 2002). It may be associated with pain, itching, and burning which lower the quality of life during and after radiotherapy (Schnur et al., 2011). Several studies indicate that acute skin reactions are risk factors for the occurrence of late skin toxicities (Lilla et al., 2007). Furthermore, patient-related factors (Body mass index, smoking, and breast size), as well as treatment related factors (concomitant hormone treatment and dose distribution), could be predictive of severe side effects to the skin during radiotherapy (De Langhe et al., 2014).

Tortorelli (2013) reported that one of the most important predictors for acute dermatitis is dose inhomogeneities of $>107 \%$ and $>110 \%$ within the target volume. So, radiotherapy techniques that enhance a more homogenous dose distribution such as intensity-modulated radiation therapy (IMRT) are associated with lower side effects (Hrsolia et al., 2007).

Sequentially application of a localized dose escalation (boost) to the tumor bed improves local control but leads to an aggravation of skin toxicities and poorer cosmetic results as established by several randomized trials (Bartelink et al., 2015, Brouwers et al., 2016).

This study aimed to assess the relationship between patient, tumor and treatment as potential risk factors, and the frequencies of radiation toxicity.

\section{Materials and Methods}

This was a prospective study of postmenopausal patients with early breast cancer who received adjuvant radiotherapy (RT) at the clinical oncology department (Assiut University Hospital, Assiut, Egypt) between January 2015 and December 2018. Only patients with operable breast cancer were selected, and they should be hormone receptor positive. All eligible patients included in this study were randomized by a simple randomization manner in a 1:1 ratio before receiving either sequential or concurrent letrozole ( $2.5 \mathrm{mg}$ daily orally for 5 years) with RT. Patients with HER2-neu positive disease were given trastuzumab treatment after RT. Radiation was either to the whole breast (after breast conservative surgery) and chest wall after mastectomy, regional lymph nodes like supraclavicular or internal mammary lymph node, or both were irradiated when indicated. Opposed medical and lateral tangential fields and wedges were used to compensate for missing tissues in the irradiation of the tumor bed and chest wall. Direct portal for supraclavicular lymph node irradiation and wide tangential fields were used to treat internal mammary lymph nodes. Two-dimensional planning was used at a dose of $50 \mathrm{~Gy}$ in 25 fractions over 5 weeks (2 Gy per fraction). A single anterior photon field for the supraclavicular region to a total dose of $50 \mathrm{~Gy}$ was applied. Boost was given either by photon beam or electron beam energy $9-18 \mathrm{MeV}$ at a dose of $10 \mathrm{~Gy}$ in a $2 \mathrm{GY}$ per fraction for a week after BCS was used according to guidelines. A teletherapy Cobalt-60 machine (Nordon, Elite 100) and Linear accelerator (Primus, Siemens) were utilized to treat the patients in the study with RT. Early and late toxicities of radiation to the lung, heart, and skin were analyzed prospectively using the Radiation Therapy Oncology Group and the European Organization for Research and Treatment of Cancer (RTOG/EORTC) (Cox et al., 1995). Early radiation toxicity was defined as occurring in 90 days while late radiation occurred after 90 days.

The protocol was approved by the local institutional boards and ethics committee of Assiut University. All patients provided written informed consent.

\section{Statistical analysis}

Numerical variables are presented as the mean \pm standard deviation and categorical variables are presented as count and percent. Student's t-test was used to compare the numerical variables. Pearson's $\chi^{2}$ test was used to compare independent categorical variables. Multivariate logistic regression analysis was performed to identify the predictors of skin, cardiac, and pulmonary toxicity. A p-value $<0.05$ was regarded as statistically significant. Statistical analysis was performed using SPSS software

Table 1. Acute Skin Toxicity in Association with Patientand Therapy-Related Characteristics

$$
\text { Acute skin toxicity }
$$

\begin{tabular}{|c|c|c|c|c|}
\hline Data & No $(n=54)$ & $\leq \mathrm{G} 2(\mathrm{n}=9)$ & $>\mathrm{G} 2(\mathrm{n}=12)$ & $\mathrm{P}$ value \\
\hline \multicolumn{5}{|c|}{ Hormonal treatment } \\
\hline Sequential & $32(59.3 \%)$ & $4(44.4 \%)$ & $4(33.3 \%)$ & 0.22 \\
\hline Concurrent & $22(40.7 \%)$ & $5(55.6 \%)$ & $8(66.7 \%)$ & \\
\hline \multicolumn{5}{|l|}{ BMI } \\
\hline$<25 \mathrm{~kg} / \mathrm{m}^{2}$ & $5(9.3 \%)$ & 0 & $2(16.7 \%)$ & 0.43 \\
\hline$\geq 25 \mathrm{~kg} / \mathrm{m}^{2}$ & $49(90.7 \%)$ & $9(100 \%)$ & $10(83.3 \%)$ & \\
\hline \multicolumn{5}{|l|}{$\mathrm{DM}$} \\
\hline Yes & $13(24.1 \%)$ & $1(11.1 \%)$ & $4(33.3 \%)$ & 0.49 \\
\hline No & $41(75.9 \%)$ & $8(88.9 \%)$ & $8(66.7 \%)$ & \\
\hline \multicolumn{5}{|l|}{ HTN } \\
\hline Yes & $21(38.9 \%)$ & $4(44.4 \%)$ & $2(16.7 \%)$ & 0.29 \\
\hline No & $33(61.1 \%)$ & $5(55.6 \%)$ & $10(83.3 \%)$ & \\
\hline \multicolumn{5}{|l|}{ Tumor side } \\
\hline Left & $28(51.9 \%)$ & $3(33.3 \%)$ & $6(50 \%)$ & 0.58 \\
\hline Right & $26(48.1 \%)$ & $6(66.7 \%)$ & $6(50 \%)$ & \\
\hline \multicolumn{5}{|l|}{ Chemotherapy } \\
\hline $\begin{array}{l}\text { Anthracycline } \\
\text { with taxane }\end{array}$ & $8(14.8 \%)$ & $3(33.3 \%)$ & $3(25 \%)$ & 0.44 \\
\hline $\begin{array}{l}\text { Anthracycline- } \\
\text { based }\end{array}$ & $41(75.9 \%)$ & $6(66.7 \%)$ & $9(75 \%)$ & \\
\hline No & $5(9.3 \%)$ & 0 & 0 & \\
\hline \multicolumn{5}{|c|}{ Trastuzumab treatment } \\
\hline Yes & $7(13 \%)$ & $3(33.3 \%)$ & $5(41.7 \%)$ & 0.03 \\
\hline No & $47(87 \%)$ & $6(66.7 \%)$ & $7(58.3 \%)$ & \\
\hline \multicolumn{5}{|l|}{ Nodal irradiation } \\
\hline No & $6(11.1 \%)$ & $1(11.1 \%)$ & $1(8.3 \%)$ & 0.96 \\
\hline Yes & $48(88.9 \%)$ & $8(88.9 \%)$ & $11(91.7 \%)$ & \\
\hline \multicolumn{5}{|l|}{ Boost irradiation } \\
\hline Yes & $2(3.7 \%)$ & $5(55.6 \%)$ & $7(58.3 \%)$ & 0.01 \\
\hline No & $52(92.3 \%)$ & $4(44.4 \%)$ & $5(41.7 \%)$ & \\
\hline
\end{tabular}

Data expressed as frequency (percentage). $\mathrm{P}$ value was significant if $<0.05$ and is shown in bold. BMI, body mass index; DM, diabetes mellitus; HTN, hypertension. 
Table 2. Late Skin Toxicity in Association with Demographic Data

\begin{tabular}{|c|c|c|c|c|}
\hline \multirow[b]{2}{*}{ Data } & \multicolumn{4}{|c|}{ Late skin toxicity } \\
\hline & No $(n=62)$ & $\leq \mathrm{G} 2(\mathrm{n}=6)$ & $>\mathrm{G} 2(\mathrm{n}=7)$ & $\mathrm{P}$ value \\
\hline \multicolumn{5}{|c|}{ Hormonal treatment } \\
\hline Sequential & $35(56.5 \%)$ & $2(33.3 \%)$ & $3(42.9 \%)$ & 0.46 \\
\hline Concurrent & $27(43.5 \%)$ & $4(66.7 \%)$ & $4(57.1 \%)$ & \\
\hline \multicolumn{5}{|l|}{ BMI } \\
\hline$<25 \mathrm{~kg} / \mathrm{m}^{2}$ & $6(9.7 \%)$ & $1(16.7 \%)$ & 0 & 0.57 \\
\hline$\geq 25 \mathrm{~kg} / \mathrm{m}^{2}$ & $56(90.3 \%)$ & $5(83.3 \%)$ & $7(100 \%)$ & \\
\hline \multicolumn{5}{|l|}{ DM } \\
\hline Yes & $16(25.8 \%)$ & $1(16.7 \%)$ & $1(14.3 \%)$ & 0.72 \\
\hline No & $46(74.2 \%)$ & $5(83.3 \%)$ & $6(85.7 \%)$ & \\
\hline \multicolumn{5}{|l|}{ HTN } \\
\hline Yes & $21(33.9 \%)$ & $3(50 \%)$ & $3(42.9 \%)$ & 0.67 \\
\hline No & $41(66.1 \%)$ & $3(50 \%)$ & $4(57.1 \%)$ & \\
\hline \multicolumn{5}{|l|}{ Tumor side } \\
\hline Left & $32(51.6 \%)$ & $2(33.3 \%)$ & $3(42.9 \%)$ & 0.65 \\
\hline Right & $30(48.4 \%)$ & $4(66.7 \%)$ & $4(57.1 \%)$ & \\
\hline \multicolumn{5}{|l|}{ Chemotherapy } \\
\hline $\begin{array}{l}\text { Anthracycline } \\
\text { with taxane }\end{array}$ & $11(17.7 \%)$ & $2(33.3 \%)$ & $1(14.3 \%)$ & 0.73 \\
\hline $\begin{array}{l}\text { Anthracycline } \\
\text {-based }\end{array}$ & $46(74.2 \%)$ & $4(66.7 \%)$ & $6(85.7 \%)$ & \\
\hline No & $5(8.1 \%)$ & 0 & 0 & \\
\hline \multicolumn{5}{|c|}{ Trastuzumab treatment } \\
\hline Yes & $12(19.4 \%)$ & 0 & $3(42.9 \%)$ & 0.14 \\
\hline No & $50(80.6 \%)$ & $6(100 \%)$ & $4(57.1 \%)$ & \\
\hline \multicolumn{5}{|l|}{ Nodal irradiation } \\
\hline No & $6(9.7 \%)$ & $1(16.7 \%)$ & $1(14.3 \%)$ & 0.24 \\
\hline Yes & $56(90.3 \%)$ & $5(83.3 \%)$ & $6(85.7 \%)$ & \\
\hline \multicolumn{5}{|l|}{ Boost irradiation } \\
\hline Yes & $3(4.8 \%)$ & $4(66.7 \%)$ & $7(100 \%)$ & $<0.001$ \\
\hline No & $59(95.2 \%)$ & $2(33.3 \%)$ & 0 & \\
\hline
\end{tabular}

Data expressed as frequency (percentage). $\mathrm{P}$ value was significant if $<0.05$. BMI: body mass index; DM, diabetes mellitus; HTN, hypertension

version 23.0.

\section{Results}

The mean age of all 75 patients was 59.47 years (range, $44-80$ years). The body mass index (BMI) $\geq 25 \mathrm{Kg} / \mathrm{m} 2$ was detected in $90.7 \%$ of patients. Hypertension and diabetes were diagnosed in $36 \%$ and $24 \%$ of patients respectively. There was no heart disease in all investigated patients. There was no heart disease in all investigated patients. All patients had hormonal receptor-positive disease but $20 \%$ of them had a positive HER2-neu disease.

As regards treatment of the studied patients, nodal irradiation was administered in $10.7 \%$ of patients, and boost radiotherapy was applied in $18.7 \%$ of them. $74.7 \%$ of studied patients received anthracycline only based chemotherapy, $18.7 \%$ received taxane after anthracycline chemotherapy, while $6.6 \%$ only did not receive any adjuvant chemotherapy. Trastuzumab was used for the treatment of $20 \%$ of patients.
Table 3. Association between Patient- and TherapyRelated Variables and Late Cardiac Toxicity

\begin{tabular}{|c|c|c|c|}
\hline \multirow[b]{2}{*}{ Data } & \multicolumn{3}{|c|}{ Late cardiac toxicity } \\
\hline & No $(n=61)$ & $>\mathrm{G} 2(\mathrm{n}=14)$ & $P$ value \\
\hline \multicolumn{4}{|l|}{ Hormonal treatment } \\
\hline Sequential & $32(52.5 \%)$ & $8(57.1 \%)$ & 0.49 \\
\hline Concurrent & $29(47.5 \%)$ & $6(42.9 \%)$ & \\
\hline \multicolumn{4}{|l|}{ BMI } \\
\hline$<25 \mathrm{~kg} / \mathrm{m}^{2}$ & $7(11.5 \%)$ & 0 & 0.22 \\
\hline$\geq 25 \mathrm{~kg} / \mathrm{m}^{2}$ & $54(88.5 \%)$ & $14(100 \%)$ & \\
\hline \multicolumn{4}{|l|}{$\mathrm{DM}$} \\
\hline Yes & $13(21.3 \%)$ & $5(35.7 \%)$ & 0.21 \\
\hline No & $48(78.7 \%)$ & $9(64.3 \%)$ & \\
\hline \multicolumn{4}{|l|}{ HTN } \\
\hline Yes & $17(27.9 \%)$ & $10(71.4 \%)$ & $<0.001$ \\
\hline No & $44(72.1 \%)$ & $4(28.6 \%)$ & \\
\hline \multicolumn{4}{|l|}{ Tumor side } \\
\hline Left & $29(47.5 \%)$ & $8(57.1 \%)$ & 0.36 \\
\hline Right & $32(52.2 \%)$ & $6(42.9 \%)$ & \\
\hline \multicolumn{4}{|l|}{ Chemotherapy } \\
\hline $\begin{array}{l}\text { Anthracycline with } \\
\text { taxane }\end{array}$ & $10(16.4 \%)$ & $4(28.6 \%)$ & 0.56 \\
\hline Anthracycline-based & $47(77 \%)$ & $9(64.3 \%)$ & \\
\hline No & $4(6.6 \%)$ & $1(7.1 \%)$ & \\
\hline \multicolumn{4}{|l|}{ Trastuzumab treatment } \\
\hline Yes & $10(16.4 \%)$ & $5(35.7 \%)$ & 0.1 \\
\hline No & $51(83.6 \%)$ & $9(64.3 \%)$ & \\
\hline \multicolumn{4}{|l|}{ Nodal irradiation } \\
\hline No & $7(11.5 \%)$ & $1(7.1 \%)$ & 0.53 \\
\hline Yes & $54(88.5 \%)$ & $13(92.9 \%)$ & \\
\hline \multicolumn{4}{|l|}{ Boost irradiation } \\
\hline Yes & $13(21.3 \%)$ & $1(7.1 \%)$ & 0.2 \\
\hline No & 48 (78.7\%) & $13(92.9 \%)$ & \\
\hline
\end{tabular}

Data expressed as frequency (percentage). $\mathrm{P}$ value was significant if $<0.05$. BMI, body mass index; DM, diabetes mellitus; HTN, hypertension, RTL, radiotherapy

In terms of the influencing factors for acute skin dermatitis, univariate analyses showed a significant difference between patients with $\leq \mathrm{G} 2$ acute skin toxicity $(33.3 \%)$ and those with $>$ G2 toxicity $(41.7 \%)$ who received trastuzumab therapy in comparison to those without acute skin toxicity (13\%). Also, patients who received boost RT had a significantly higher $>\mathrm{G} 2$ acute skin toxicity $(58.3 \%)$ than patients with no toxicity $(3.7 \%)$ as shown in Table 1.

With multivariate regression analysis showed that use of trastuzumab (odds ratio $=4.53,95 \% \mathrm{CI}=1.27-16.14, \mathrm{P}=$ 0.01 ) and boost irradiation (odds ratio $=4.61,95 \% \mathrm{CI}=$ $1.33-15.93, \mathrm{P}=0.01$ ) are predictors for acute skin toxicity.

Table 2 shows the association between the characteristics of patients and therapy-related risk factors with late skin toxicity. It was noticed that different grades of late skin toxicity had insignificant differences regarding baseline data except patients with $>\mathrm{G} 2$ late skin toxicity who received boost irradiation.

Multivariate regression analysis, boost irradiation 
wasn't predictor for late skin toxicity (odds ratio $=1.68$, $95 \% \mathrm{CI}=0.49-5.67, \mathrm{P}=0.40)$.

None of enrolled patients had late cardiac toxicity $\leq$ G2 while 14 patients from all studied patients had late cardiac toxicity $>$ G2. It was noticed that patients with late cardiac toxicity $>\mathrm{G} 2$ had insignificant differences as regarding baseline demographic data with exception of significantly higher frequency of hypertension among patients with late cardiac toxicity $>$ G2 $10(71.4 \%)$ vs. 17 $(27.9 \%) ; \mathrm{P}<0.001)$ as shown in table 3 .

Multivariate regression analysis, hypertension wasn't a predictor for late cardiac toxicity (odds ratio $=2.05$, $95 \% \mathrm{CI}=0.58-7.18, \mathrm{P}=0.26)$.

It was noticed that patients with different grades of late pulmonary toxicity had insignificant factors influencing their toxicity.

\section{Discussion}

Here, we prospectively investigated 75 postmenopausal early breast cancer patients undergoing adjuvant RT after surgery with either sequential or concurrent letrozole therapy. We analyzed the predictive risk factors that may affect radiation toxicity of the skin, Heart and lung. In the present study, Trastuzumab administration was fond to decrease the incidence of acute dermatitis this was agreed with De Langhe et al., (2014). which reported lower rate of acute dermatitis when trastuzumab used concurrently with radiation. It is in contradiction with the observation of Halyard et al., (2009) who reported no difference in toxicity with trastuzumab administration concurrently with adjuvant radiotherapy.

Our data support that the incidence of acute skin toxicity was significantly higher in patients receiving boost irradiation, but this is not in agreement of the results of the study done by Borm et al., (2018) who stated that boost RT is not a predictor for the increase of acute skin toxicity. Other predictive factors were found to influence radiation induced skin toxicity like bra cup size, and regular bra wearing as reported by Thongkhao et al., (2019) that regular bra-wearing during radiotherapy, in comparison to non-bra-wearing, resulted in significantly lower rates of $\geq \mathrm{G} 2$ acute skin toxicity. The results of Malekzadeh et al., (2017) suggest that usage of Achillea millefolium, especially at lower doses of radiation, might decrease radiation induced dermatitis. BMI, smoking and large breast volume as detected in some studies (De Langhe et al., 2014; Freedman et al., 2006; Goldsmith et al., 2011). In the current study multivariate analysis done for late cardiac toxicity in association to demographic data and showed that hypertension was not a predictor for late cardiac toxicity. These results were in agreement with results of a study published by Khan et al., (2014) who demonstrated that the risk of $\geq$ grade 2 cardiotoxicity was associated with smoking, BMI $\geq 25$ and left sided RT but not hypertension, chemotherapy or hormonal therapy. We also conducted an analysis of risk factors for radiationinduced pulmonary toxicities of breast cancer patients, but no significant demographic or therapy-related factors detected. Some studies reported that age and doses of chemotherapy drugs were risk factors for acute radiation lung injury (Vujaskovic et al., 2002; Ozturk et al., 2004). Matzinger et al., (2010) compared the incidence of acute radiation lung injury between internal mammary lymph nodes (IMNs) irradiation plus supraclavicular region irradiation and IMNs irradiation only and concluded that the incidence was $4.3 \%$ and $1.3 \%$, respectively.

Wang et al., (2017) published that hypertension is an independent risk factor for acute lung toxicity and trastuzumab use is a risk factor for late radiation lung injury.

In conclusion, this study concluded that trastuzumab use decreases the incidence of acute dermatitis but boost irradiation increases it. Breast cancer patients that survive for a long time should be monitored for risk factors of their treatment schedule.

\section{References}

A Thongkhao P, Peerawong T, Bridhikitti J, et al (2019). Effects of regular bra-wearing on acute skin toxicity in breastconserving radiotherapy women. Asian Pac J Cancer Care, 4, 157-64.

Bartelink H, Maingon P, Poortmans P (2015). Whole-breast irradiation with or without a boost for patients treated with breast-conserving surgery for early breast cancer: 20 -year follow-up of a randomized phase 3 trial. Lancet Oncol, 16, 47-56.

Bernchou U, Schytte T, Bertelsen A (2013). Time evolution of regional $\mathrm{CT}$ density changes in normal lung after IMRT for NSCLC. Radiother Oncol, 109, 89-4.

Borm KJ, Loos M, Oechsner M (2018). Acute radiodermatitis in modern adjuvant 3D conformal radiotherapy for breast cancer - the impact of dose distribution and patient related factors. Radiat Oncol, 13, 218.

Bradley J, Movsas B (2008). Radiation pneumonitis and esophagitis in thoracic irradiation: Radiation Toxicity: A Practical Guide. Springer US, Boston, MA, pp 43-64.

Bray F, Ferlay J, Soerjomataram I (2018). GLOBOCAN Estimates of Incidence and Mortality Worldwide for 36 Cancers in 185 Countries. CA Cancer J Clin, 68, 394-4.

Brouwers PJAM, van Werkhoven E, Bartelink H (2016). Factors associated with patient-reported cosmetic outcome in the young boost breast trial. Radiother Oncol, 120, 107-13.

Burris HA, Hurtig J (2010). Radiation recall with anticancer agents. Oncologist, 15, 1227.

Chen H, Senan S, Nossent EJ (2017). Treatment-related toxicity in patients with early-stage non-small cell lung cancer and coexisting interstitial lung disease: a systematic review. Int $J$ Radiat Oncol Biol Phys, 98, 622-1.

Cox JD, Stetz J, Pajak TF (1995). Toxicity criteria of the Radiation Therapy Oncology Group (RTOG) and the Europe $\neg$ an Organization for Research and Treatment of Cancer (EORTC). Int J Radiat Oncol Biol Phys, 31, 1341-6.

De Langhe S, Mulliez T, Veldeman L (2014). Factors modifying the risk for developing acute skin toxicity after whole-breast intensity modulated radiotherapy. BMC Cancer, 14, 711.

Early Breast Cancer Trialists' Collaborative Group (2011). Effect of radiotherapy after breast-conserving surgery on 10-year recurrence and 15-year breast cancer death: meta-analysis of individual patient data for 10801 women in 17 randomized trials. Lancet, 378, 771-4.

Ebert N, Baumann M, Troost EGC (2015). Radiation-induced lung damage - clinical risk profiles and predictive imaging on their way to risk-adapted individualized treatment planning?. Radiother Oncol, 117, 1-3. 
Freedman GM, Anderson PR, Li JS (2006). Intensity modulated radiation therapy (IMRT) decreases acute skin toxicity for women receiving radiation for breast cancer. Am J Clin Oncol-Cancer Clinical Trials, 29, 66-70.

Goldsmith C, Haviland J, Tsang Y (2011). Large breast size as a risk factor for late adverse effects of breast radiotherapy: Is residual dose inhomogeneity, despite 3D treatment planning and delivery, the main explanation?. Radiother Oncol, 100, 236.

Halyard MY, Pisansky TM, Dueck AC, Suman V, Pierce L (2009). Radiotherapy and adjuvant trastuzumab in operable breast cancer: tolerability and adverse event data from the NCCTG Phase III Trial N9831. J Clin Oncol, 27, 2638-4.

Harsolia A, Kestin L, Grills I (2007). Intensity-modulated radiotherapy results in significant decrease in clinical toxicities compared with conventional wedge-based breast radiotherapy. Int J Radiat Oncol Biol Phys, 68, 1375.

Jagsi R, Griffith KA, Koelling T (2007). Rates of myocardial infarction and coronary artery disease and risk factors in patients treated with radiation therapy for early-stage breast cancer. Cancer, 109, 650-7.

Jeba J, Isiah R, Subhashini J (2015). Radiation pneumonitis after conventional radiotherapy for breast cancer: a prospective study. J Clin Diagn Res, 9, XC01-XC05.

Khan M, Gupta M, Seam R (2014). Analysis of cardiac adverse events following postmastectomy hypofractionated radiotherapy. Chin Clin Oncol, 3, 47. 2304-5.

Lilla C, Ambrosone CB, Kropp S (2007). Predictive factors for late normal tissue complications following radiotherapy for breast cancer. Breast Cancer Res Treat, 106, 143.

Lopez E, Nunez MI, Guerrero MR (2002). Breast cancer acute radiotherapy morbidity evaluated by different scoring systems. Breast Cancer Res Treat, 73, 127-4.

Malekzadeh M, Sandoughdaran S, Homayi Shandiz F, Honary S (2017). The efficacy of Licorice Root (Glycyrrhiza glabra) and Yarrow (Achillea millefolium) in preventing radiation dermatitis in patients with breast cancer: A randomized, double-blinded, placebo-controlled clinical trial. Asian Pac $J$ Cancer Care, 1, 9.

Matzinger O, Heimsoth I, Poortmans P (2010). Technical factors associated with radiation pneumonitis after local-regional radiation therapy for breast cancer. Acta Oncol, 49, 24-4.

Ozturk B, Egehan M, Atavci S (2004). Pentoxifylline in prevention of radiation induced lung toxicity in patients with breast and lung cancer: a double blind randomize trial. Int $J$ Radiat Oncol Biol Phys, 58, 213-9.

Schnur JB, Ouellette SC, Dilorenzo TA, Green S, Montgomery GH (2011). A qualitative analysis of acute skin toxicity among breast cancer radiotherapy patients. Psychooncology, 20, 260-8.

Tortorelli G, Di Murro L, Barbarino R (2013). Standard or hypofractionated radiotherapy in the postoperative treatment of breast cancer: a retrospective analysis of acute skin toxicity and dose inhomogeneities. BMC Cancer, 13, 230.

Vogelius IR, Bentzen SM (2012). A literature-based meta-analysis of clinical risk factors for development of radiation induced pneumonitis. Acta Oncol, 51, 975-3.

Vujaskovic Z, Feng QF, Rabbani ZN (2002). Assessment of the protective effect of amifostine on radiation-induced pulmonary toxicity. Exp Lung Res, 28, 577.

Wang Q, Jie W, Liang Z, Wu H, Cheng J (2017). Postmastectomy intensity modulation radiated therapy of chest wall and regional nodes Retrospective analysis of the performance and complications up for 5 years. Medicine, 96, 39(e7956).

Yarnold J, Vozenin Brotons MC (2010). Pathogenetic mechanisms in radiation fibrosis. Radiother Oncol, 97, 149-61.

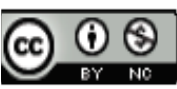

This work is licensed under a Creative Commons AttributionNon Commercial 4.0 International License. 